\title{
Penerapan Sasaran Keselamatan Pasien \\ di Rumah Sakit
}

\author{
Eka Rosliani Nasution \\ ekaroslianinasution1303@gmail.com
}

\begin{abstract}
Abstrak
Keselamatan pasien merupakan sistem pemberian asuhan yang aman bagi pasien di rumah sakit. Pemberian asuhan yang aman adalah penurunan tindakan yang tidak aman kepada pasien dan pemberian tindakan terbaik untuk mendapatkan derajat kesehatan pasien yang optimal dalam sistem pelayanan kesehatan. Keselamatan menjadi isu global dan terangkum dalam lima isu penting yang terkait di rumah sakit yaitu keselamatan pasien, keselamatan pekerja atau petugas kesehatan, keselamatan bangunan dan peralatan di rumah sakit, keselamatan lingkungan dan keselamatan bisnis rumah sakit yang terkait dengan kelangsungan hidup rumah sakit. Mengingat masalah keselamatan pasien merupakan masalah yang perlu ditangani segera maka diperlukan standar keselamatan pasien fasilitas pelayanan kesehatan yang merupakan acuan untuk melaksanakan kegiatannya. Berdasarkan Permenkes RI Nomor 11 Tahun 2017 tentang Keselamatan Pasien bahwa setiap fasilitas pelayanan kesehatan harus menyelenggarakan keselamatan pasien. Sasaran Keselamatan Pasien merupakan suatu bagian dari Standar Akreditasi Rumah Sakit yang harus dapat diterapkan di rumah sakit yang berguna dalam meningkatkan pelayanan kesehatan yang berkualitas. Pengetahuan tenaga kesehatan dalam Sasaran Keselamatan Pasien terdiri dari ketepatan identifikasi pasien, peningkatan komunikasi yang efektif, peningkatan keamanan obat yang perlu diwaspadai kepastian tepat lokasi, tepat prosedur, dan tepat pasien operasi, pengurangan risiko infeksi terkait pelayanan kesehatan, pengurangan risiko pasien jatuh. Bagi tenaga kesehatan khususnya dokter dan perawat diwajibkan untuk mengetahui tentang Sasaran Keselamatan Pasien.
\end{abstract}

\section{Pendahuluan}

\section{Latar Belakang}

Sistem pelayanan kesehatan yang perlu mendapatkan perhatian tentang keselamatan pasien bahkan sudah menjadi isu dunia saat ini. Keselamatan pasien merupakan hak bagi setiap pasien di dalam menerima pelayanan kesehatan karena salah satu prinsip dasar di dalam memberikan pelayanan kesehatan pada pasien. Kementrian Kesehatan Republik Indonesia (2015) menjadikan hak pasien sebagai standar pertama pada tujuh standar keselamatan pasien rumah sakit.World Health Organization (WHO) Collaborating Center for Patient Safety Solutions bekerja sama dengan Joint Comission and Joint Comission International telah memasukkan masalah keselamatan pasien dengan menerbitkan enam program kegiatan keselamatan pasien pada 2005 dan sembilan panduan solusi keselamatan pasien di rumah sakit pada 2007 Kondisi Potensial Cedera (KPC) merupakan 
kondisi yang sangat berpotensi untuk menimbulkan cedera, tetapi belum terjadi insiden. Kejadian Nyaris Cedera (KNC) merupakan terjadinya insiden yang belum sampai terpapar ke pasien. Kejadian Tidak Cedera (KTC) merupakan insiden yang sudah terpapar ke pasien, tetapi tidak timbul cedera. Kejadian Tidak Diharapkan (KTD) merupakan Insiden yang mengakibatkan cedera pada pasien. Suatu Kejadian Tidak Diharapkan (KTD) yang mengakibatkan kematian, cedera permanen, atau cedera berat yang temporer dan membutuhkan intervensi untuk mempetahankan kehidupan, baik fisik maupun psikis, yang tidak terkait dengan perjalanan penyakit atau keadaan pasien disebut sebagai Kejadian sentinel.

Keselamatan menjadi isu global dan terangkum dalam lima isu penting yang terkait di rumah sakit yaitu keselamatan pasien, keselamatan pekerja atau petugas kesehatan, keselamatan bangunan dan peralatan di rumah sakit yang bisa berdampak terhadap keselamatan pasien dan petugas. Keselamatan lingkungan yang berdampak terhadap pencemaran lingkungan dan keselamatan bisnis rumah sakit yang terkait dengan kelangsungan hidup rumah sakit. Keselamatan pasien merupakan prioritas utama untuk dilaksanakan terkait dengan isu mutu dan citra perumahsakitan. Gerakan (Patient Safety) keselamatan pasien telah menjadi spirit dalam pelayanan rumah sakit seluruh dunia tidak hanya rumah sakit di negara maju yang menerapkan keselamatan pasien untuk menjamin mutu pelayanan, tetapi juga rumah sakit di negara berkembang seperti di Indonesia (Depkes, 2006). Kementerian Kesehatan Republik Indonesia telah mengeluarkan Peraturan Menteri Kesehatan No. 11 Tahun 2017 tentang Keselamatan Pasien di Rumah Sakit. Peraturan ini menjadi tonggak utama operasionalisasi keselamatan pasien di rumah sakit seluruh Indonesia. Banyak rumah sakit di Indonesia yang telah berupaya membangun dan mengembangkan keselamatan pasien, namun upaya tersebut dilaksanakan berdasarkan pemahaman manajemen terhadap keselamatan pasien. Peraturan menteri ini memberikan panduan bagi manajemen rumah sakit agar dapat menjalankan spirit keselamatan pasien secara utuh.

Patient safety merupakan prioritas, isu penting dan global dalam pelayanan kesehatan (Perry 2009). Ballard (2003) dalam Mustikawati (2011) menyatakan bahwa Patient safety merupakan komponen penting dan vital dalam asuhan keperawatan yang berkualitas. Hal ini menjadi penting karena Patient safety merupakan suatu langkah untuk memperbaiki mutu pelayanan dalam memberikan asuhan keperawatan (Cahyono, 2008). Inti dari patient safety yaitu penghindaran, pencegahan dan perbaikan dari kejadian yang tidak diharapkan atau mengatasi cedera-cedera dari proses pelayanan kesehatan (Ballard, 2003). Sehingga, program utama patient safety yaitu suatu usaha untuk menurunkan angka kejadian tidak diharapkan (KTD) yang sering terjadi pada pasien selama dirawat di rumah sakit yang sangat merugikan baik pasien maupun pihak rumah sakit.

Keselamatan Pasien adalah suatu sistem yang membuat asuhan pasien lebih aman, meliputi assesment risiko, identifikasi dan pengelolaan risiko pasien, pelaporan dan analisis insiden, kemampuan belajar dari insiden dan tindak lanjutnya, serta implementasi solusi untuk meminimalkan timbulnya risiko dan mencegah terjadinya cedera yang disebabkan oleh kesalahan akibat melaksanakan suatu tindakan atau tidak mengambil tindakan yang seharusnya diambil (Permenkes, 2011). Keenam aspek tersebut sangat penting untuk dilaksanakan di setiap rumah sakit. Namun harus diakui kegiatan institusi rumah sakit dapat berjalan apabila ada pasien. Keselamatan pasien merupakan prioritas utama untuk dilaksanakan dan hal tersebut terkait dengan isu mutu dan citra perumahsakitan (Depkes, 2011).

Keselamatan pasien di rumah sakit (KPRS) adalah system pelayanan dalam suatu Rumah sakit yang memberikan asuhan pasien menjadi lebih aman, termasuk didalamnya mengukur resiko, identifikasi dan pengelolahan resiko terhadap pasien analisa insiden, kemampuan untuk belajar dan 
menindaklanjuti insiden serta menerapkan solusi untuk mengurangi resiko (WHO,2004). Oleh karena itu diperlukan komitmen dan ethis dalam keperawatan. Keselamatan pasien merupakan suatu system yang sangat dibutuhkan dan dengan adanya system ini diharapkan dapat meminimalisir kesalahan dalam penanganan pasien baik pada pasien UGD, rawat inap maupun pasien poliklinik (PERSI, 2008).

Rumah Sakit merupakan institusi pelayanan kesehatan bagi masyarakat dengan karakteristik tersendiri yang dipengaruhi oleh perkembangan ilmu pengetahuan kesehatan, kemajuan teknologi dan kehidupan sosial ekonomi masyarakat. Sistem Akreditasi Rumah Sakit (KARS) versi 2012 menjelaskan bahwa seluruh kegiatan pelayanan dirumah sakit yang harus memberikan pelayanan yang memenuhi standar kualitas serta jaminan rasa aman dan perlindungan terhadap dampak pelayanan yang diberikan dalam rangka memenuhi hak-hak masyarakat akan pelayanan yang berkualitas serta aman. Dalam hal ini rumah sakit melaksanakan program-program mutu dan keselamatan pasien. Keselamatan pasien rumah sakit adalah suatu sistem dimana rumah sakit membuat asuhan pasien lebih aman dengan mencegah terjadinya cedera yang disebabkan oleh kesalahan akibat melaksanakan suatu tindakan atau tidak mengambil tindakan yang seharusnya diambil.

Peningkatan mutu pada keselamatan pasien perlu melibatkan dokter, perawat dan semua orang yang bekerja di sistem kesehatan wajib berkomitmen untuk merawat, membantu, menghibur dan merawat pasien dan memiliki keunggulan dalam penyediaan layanan kesehatan untuk semua orang yang membutuhkannya agar terwujud peningkatan keselamatan pasien di tatanan pelayanan kesehatan sebagai suatu bagian dalam sistem pelayanan kesehatan .

\section{Metode}

Metode penelitian ini dilakukan dengan cara Pengumpulan data di peroleh dengan cara mengidentifikasi pengetahuan dan pelaksanaan prosedur keselamatan pasien rumah sakit yang terdapat dalam beberapa jurnal keperawatan. Data yang di kumpulkan kemudian diolah dan dianalisis . Teknik analisis data yang digunakan yaitu analisis univariat yakni untuk mengetahui hubungan dari karakteristik responden dan masing-masing variabel yang di teliti. selain melakukan analisis univariat kedua variabel akan dilakukan krostabulasi. Datayangtelahdianalisisakan disajikan dalam bentuk jurnal. Data dikumpulkan melalui analisa setiap jurnal tentang keselamatan pasien.

\section{Hasil}

Berdasarkan hasil penelitian dan teori diatas dapat disimpulkan bahwa supervisi merupakan aktivitas yang harus rutin dilakukan guna mencapai implementasi sasaran keselamatan pasien yang lebih optimal sehingga keselamatan pasien akan menjadi prioritas pada setiap aktivitas dan penerapannya menjadi budaya yang harus dilakukan oleh seluruh perawat tanpa terkecuali.Hasil penelitian ini didukung dengan hasil penelitian yang telah dilakukan oleh (Nurmalia, Devi. Hanny Handiyani, n.d.) bahwa kelompok yang tidak mendapatkan pengawasan atau supervisi akan beresiko mengalami penurunan dalam penerapan budaya keselamatan pasien (Irawan AG, Yulia Sri, 2017; Utami, Saparwati, \& Siswanto, 2016).

Kendala dalam pelaksanaan sasaran keselamatan pasien dipengearuhi oleh kurangnya sosialisasi, motivasi, pengawasan, dukungan dari manajemen rumah sakit (Sundoro et al., 2016)

Hasil Penelitian meliputi karakteristik perawat, pelaksanaan sasaran keselamatan pasien dan hubungan karakteristik dengan pelaksanan sasaran keselamatan pasien.

Dengan intervensi yang pertama alat bantu atau pegangan, jalan tandem, fisik exercise, keset 
anti slip dan latihan keseimbangan. Sedangkan berdasarkan standar pelaksanaan resiko jatuh yaitu jalan tandem, meningkatkan latihan keseimbangan dengan melakukan swiss ball, meningkatkan keseimbangan dengan melakukan physical exercise, meningkatkan keseimbangan dengan melakukan yoga dan senam ergonomis untuk membantu tubuh agar tetap bugar, daya tahan otot dan kelenturan.

\section{Pembahasan}

Sasaran Keselamatan Pasien merupakan syarat untuk diterapkan di semua rumah sakit yang diakreditasi oleh Komisi Akreditasi Rumah Sakit. Penyusunan sasaran ini mengacu kepada Nine Life-Saving Patient Safety Solutions dari WHO Patient Safety (2007) yang digunakan juga oleh Komite Keselamatan Pasien Rumah Sakit PERSI (KKPRS PERSI), dan dari Joint Commission International (JCI). Maksud dari Sasaran Keselamatan Pasien adalah mendorong perbaikan spesifik dalam keselamatan pasien. Sasaran menyoroti bagian-bagian yang bermasalah dalam pelayanan kesehatan dan menjelaskan bukti serta solusi dari konsensus berbasis bukti dan keahlian atas permasalahan ini. Diakui bahwa desain sistem yang baik secara intrinsik adalah untuk memberikan pelayanan kesehatan yang aman dan bermutu tinggi, sedapat mungkin sasaran secara umum difokuskan pada solusi-solusi yang menyeluruh.

- Penerapan Sasaran Keselamatan Pasien Identifikasi Pasien

Hasil penelitian terkait identifikasi pasien menunjukkan lebih dari setengah perawat telah menerapkan kebijakan atau prosedur dalam mengidentifikasi pasien. Namun masih didapatkan perawat yang belum mengidentifikasi menggunakan dua identitas pasien, misalnya menggunakan nama dan nomor rekam medis seperti yang telah ditulis digelang identitas pasien, perawat masih menggunakan nomor kamar atau nomor tempat tidur. Rumah Sakit telah berupaya untuk memperbaiki pelaksanaan identifikasi pasien sesuai prosedur. Proses identifikasi pasien dilakukan sejak dari awal pasien masuk rumah sakit dan akan selalu dikonfirmasi dalam segala proses di rumah sakit. Semua pasien baru yang masuk telah diberikan gelang identitas dan ditanyakan namanya saat gelang disematkan, pemberian gelang tersebut untuk memudahkan proses identifikasi pasien. Pada saat pemasangan gelang identitas, pasien akan diberi tahu mengenai manfaat gelang dan perawat wajib menjelaskan risiko yang akan timbul jika tidak dipasang gelang identitas.

Menggunakan "dua identitas pasien" harus mendapat perhatian dan harus selalu disosialisasikan oleh kepala ruang dan tim keselamatan pasien. Penggunakan dua indentitas pasien untuk mengidentifikasi seorang pasien, seperti nama pasien, nomor rekam medis, tanggal lahir, gelang identitas pasien dengan bar-code, dan lain-lain. Nomor kamar pasien atau lokasi tidak boleh digunakan untuk identifikasi. Proses identifikasi pasien dapat dilakukan perawat dengan bertanya kepada pasien sebelum melakukan tindakan misalnya "nama ibu siapa?". Jika pasien menggunakan gelang tangan harus tetap dikonfirmasi secara verbal, seandainya pasien tidak dapat menyebut nama maka perawat dapat menanyakan pada penunggu atau keluarga. Pasien yang tidak mampu menyebut nama, tidak memakai gelang dan tidak ada keluarga atau penunggu maka identitas dipastikan dengan melihat rekam medik oleh dua orang petugas (Unit pelayanan jaminan mutu, RSUPN Dr. Cipto Mangunkusumo, 2011).

\section{- Komunikasi Efektif}

Hasil penelitian menunjukkan semua perawat telah melaksanakan verifikasi keakuratan komunikasi secara lisan atau melalui telepon dengan baik. Saat melakukan komunikasi dengan dokter melalui telepon, perawat sudah menyiapkan kertas untuk mencatat semua instruksi dokter 
dan mengkonfirmasi ulang apa yang sudah dicatat oleh perawat. Begitu juga saat melakukan komunikasi secara lisan atau visite dokter, jika ada tulisan dokter yang kurang jelas, perawat mengkonfirmasikan atau menanyakan kembali instruksi yang diberikan oleh dokter.

Perawat juga sudah menjelaskan semua prosedur pelayanan kesehatan mulai dari saat pasien masuk ruangan, pemeriksaan, diagnosis, rujukan dan saat pasien keluar rumah sakit. Setiap akan melakukan proses tindakan keperawatan sudah meminta persetujuan atau informed concent baik secara lisan atau pada tindakan tertentu secara tertulis. Pasien pun mempunyai hak untuk bertanya jika masih ada yang kurang jelas dalam memutuskan menerima atau menolak pelayanan kesehatan yang diberikan.

Menurut Kemenkes, (2011) komunikasi yang mudah terjadi kesalahan kebanyakan terjadi pada saat instruksi atau perintah diberikan melalui telepon. Rumah sakit wajib menerapkan standar keselamatan pasien dan wajib mengupayakan pemenuhan keselamatan pasien.

Komunikasi adalah penyebab pertama masalah keselamatan pasien. Komunikasi yang tepat, akurat, lengkap, jelas, dan dipahami oleh pasien akan mengurangi kesalahan dan menghasilkan peningkatan keselamatan pasien. Jenis komunikasi yang dapat dilakukan untuk menunjang pelaksanaan keselataman pasien menurut Sammer, Lykens, Singh, Mains, \& Lackan, (2010) diantaranya: Structured techniques (read-back, SBAR). Manojlovich, (2007) menyatakan komunikasi dokter dan perawat mempunyai peran penting dalam menentukan derajat kesehatan pasien, dan kualitas pelayanan yang diberikan. Semakin baik komunikasi diantara perawat dan dokter semakin baik hasil perawatan yang diberikan.

\section{- Keamanan Obat dan Cairan}

Salah satu tindakan yang mengancam keselamatan pasien adalah kesalahan pemberian obat yang dilakukan oleh perawat. Sebagian besar perawat telah menerapkan keamanan obat dan Cairan. Penerapan delapan benar dalam menunjang keselamatan pasien yaitu: benar pasien, benar obat, benar dosis, benar waktu, benar cara atau route pemberian, benar dokumentasi, benar informasi, dan benar pengkajian juga sudah diterapkan.

Menurut Kemenkes (2011), obat- obatan menjadi bagian dari rencana pengobatan pasien, manajemen RS harus berperan secara kritis untuk memastikan keselamatan pasien. Nama Obat, rupa dan ucapan mirip (NORUM), yang membingungkan staf pelaksana merupakan salah satu penyebab yang paling sering dalam kesalahan obat (medication error). Oleh karena itu, kewaspadaan terhadap obat-obat yang tingkat bahayanya tinggi harus ditunjukkan dengan menyimpannya di tempat khusus dan tidak di setiap ruangan. Obat-obatan lain harus dibawah pengawasan apoteker, sehingga kalau ada dosis yang berlebihan dapat disarankan ke dokternya untuk meninjau kembali terapinya.

Menurut Cohen, (2007) terdapat enam obat yang berisiko terjadinya kesalahan, diantaranya: Insulin, heparin, opioid, injeksi kalium klorida atau konsentrat kalium fosfat. blocking agen neuromuskuler, obat kemoterapi. Penelitian Clancy, (2011) menunjukkan bahwa di unit perawatan rata- rata terjadi 3.7 insiden kesalahan obat setiap enam bulan. Weant, Humpries, Hite \& Armitstead, (2010) menyatakan ribuan orang Amerika meninggal setiap tahun akibat kesalahan obat selama dirawat di rumah sakit, diperkirakan 29 milyard dollar Amerika dihabiskan tiap tahun akibat kesalahan obat. Ketepatan Lokasi, Prosedur, Pasien Operasi

Menurut Kemenkes (2011), Salah lokasi, salah prosedur, salah pasien operasi merupakan sesuatu yang mengkhawatirkan dan sering terjadi di Rumah Sakit. Kesalahan ini akibat dari 
komunikasi yang tidak efektif atau tim bedah yang kurang atau tidak melibatkan pasien saat penandaan lokasi. Di samping itu, ada beberapa faktor yang sering terjadi, antara lain: pengkajian pasien yang tidak adekuat, penelaahan ulang catatan medis tidak adekuat, budaya yang tidak mendukung komunikasi antar anggota tim bedah.

Berdasarkan hasil penelitian, sebagian besar perawat telah melakukan upaya untuk meningkatkan ketepatan lokasi, prosedur, dan pasien operasi sebelum dilakukan operasi ke pasien, antara lain melakukan pengecekan terkait identitas pasien, mengecek ketepatan prosedur dan lokasi operasi serta melakukan beberapa prosedur rutin seperti enema sesuai instruksi dokter, menganjurkan pasien untuk puasa, sebelum memberi antibiotik melakukan test alergi terlebih dahulu, menyiapkan dan mengecek hasil foto-foto rontgen dan hasil pemeriksaan lainnya. Hal ini bertujuan untuk mencegah kekeliruan lokasi, prosedur, dan pasien operasi. Pengurangan Risiko Infeksi.

Rumah sakit merupakan tempat yang rentan terjadi infeksi nosokomial atau infeksi baru selama perawatan. Meski dapat juga terjadi pada pengunjung, infeksi ini paling sering menjangkiti pasien dengan kondisi daya tahan tubuhnya sedang menurun. Adanya infeksi baru kadang-kadang juga dapat memicu dampak yang lebih fatal saat dirawat

di rumah sakit terutama saat berada di ruang bedah.

Hasil penelitian menunjukkan sebagian besar perawat telah menerapkan tindakan untuk mengurangi infeksi dengan mencuci tangan sebelum dan sesudah melakukan tindakan keperawatan, mendisinfeksi bagian tubuh yang akan dirawat luka, memakai alat- alat yang sudah disterilkan, dan memakai sarung tangan saat melakukan tindakan apapun. Didepan tiap kamar pasien juga sudah terdapat desinfektan. Hal ini menunjukkan kepedulian yang tinggi untuk mencegah infeksi yang ada di rumah sakit karena tingginya angka infeksi ini akan memicu terjadinya ketidakpuasan yang dirasakan oleh pasien sebagai konsumen rumah sakit. WHO, (2007) merekomendasikan implementasi penggunaan cairan alcohol-based hand-rubs tersedia pada titik-titik pelayanan, tersedianya sumber air pada semua kran, pendidikan staf mengenai teknik kebersihan tangan yang benar, mengingatkan penggunaan tangan bersih di tempat kerja; dan pengukuran kepatuhan penerapan kebersihan tangan melalui pemantauan/observasi dan teknik- teknik yang lain. Pengurangan Risiko Jatuh Jumlah kasus jatuh cukup bermakna sebagai penyebab cidera bagi pasien rawat inap. Mengingat risiko pasien jatuh sangat besar maka sebagai perawat perlu memikirkan berbagai cara untuk mengurangi terjadinya hal tersebut. Hal ini dilakukan dengan tujuan pasien tidak perlu di rawat di Rumah Sakit lebih lama akibat komplikasi jatuh.

Hasil penelitian menunjukkan lebih dari setengah perawat telah menerapkan usaha pencegahan jatuh dengan menaikkan pengaman atau pembatas tempat tidur. Pemasangan pengaman tempat tidur sangat penting disediakan terutama pada pasien dengan kesadaran menurun dan gangguan mobilitas. Perawat juga sudah meletakkan bel di dekat pasien dan menganjurkan pasien untuk menggunakan bel bila memerlukan bantuan, supaya tidak terjadi hal-hal tidak terduga yang mengakibatkan pasien jatuh atau membuat cidera baru. Selain itu, perawat memberikan tanda atau etiket atau label pada tangan pasien dan tanda segitiga berwarna kuning yang di letakkan di sisi tempat tidur untuk pasien risiko jatuh.

\section{Penutup}


Kesimpulan penelitian ini ada hubungan yang signifikan antara variabel pengetahuan, kesadaran diri, komunikasi dan penggunaan energi dengan budaya keselamatan pasien. Berdasarkan hasil penelitian dan pembahasan serta kesimpulan di atas, maka peneliti memiliki saran kepada pihak rumah sakit dapat meningkatkan kapasitas pengetahuan perawatnya dengan lebih sering mengikuti pelatihan sesuai bidangnya; kepala ruangan lebih aktif dalam memberi motivasi kepada perawatnya sehingga kesadaran diri mengenai pekerjaan dapat terus ditingkatkan; meningkatkan komunikasi yang baik terhadap perawatnya sehingga tidak terjadi miss komunikasi yang dapat berakibat pada terganggunya pelayanan kepada pasien; serta selalu mengingatkan kepada perawatnya agar selalu bekerja seoptimal mungkin sehingga pelayanan dapat berlangsung dengan baik dan pasien merasa mendapat pelayanan terbaik. Tenaga kesehatan baik dokter dan perawat memiliki pengetahuan yang kurang baik tentang sasaran keamanan pasien di rumah sakit, yang menunjukkan bahwa identifikasi pasien, komunikasi efektif, keamanan obat, kepastian tepat lokasi, prosedur, pasien operasi, pengendalian infeksi, pencegahan pasien jatuh belum dipahami oleh tenaga kesehatan yaitu perawat dan dokter. Diharapkan bagi rumah sakit dapat mengadakan seminar dan pelatihan secara berkala tentang Sasaran Keselamatan Pasien dan melakukan pengawasan secara optimal bagi perawat dan dokter untuk meningkatkan kualitas pelayanan kesehatan.

\section{Daftar Pustaka}

- Bernadeta, Ani. (2015). Pengetahuan Perawat Tentang keselamatan Pasien Rumah Sakit. Jurnal Care, Vol 3(1).

- Diah Arrum, Salbiah, Murniatik. (2015). Pengetahuan Tenaga Kesehatan Dalam Sasaran Keselamatan Pasien Di Rumah Sakit Sumatera Utara. Idea Nursing Journal Vol 6 (2)

- Firawati. (2012). Pelaksanaan Program Keselamatan Pasien di RSUD Solok, Jurnal Keselamatan Pasien. 6 (2), 74-77.

- Isamainar, H. (2019). Keselamatan Pasien di Rumah Sakit. Yogyakarta: Deepublish.

- Iswati. (2013). Penerapan Sasaran Keselamatan Pasien Di Rumah Sakit. Jurnal Keperawatan Adi Husada

- Kamil, H. (2017). Patient Safety. Idea Nursing Journal Vol 1No 1.

- Kemenkes RI. (2011). Permenkes RI No. 1691/Menkes/VIII/2011 tentang Keselamatan Pasien Rimah Sakit.

- Nandahani. (2017). Penerapan Standar Keselamatan Pasien RSUD Provinsi Nusa Tenggara Barat. Jurnal Kesehatan Poltekkes Ternate, Vol 11 (2), 93-108.

- Sakinah, S., dkk. (2017). Analisis Sasara Keselamatan Pasien Dilihat dari Aspek Pelaksanan Identifikasi Pasien dan Keamanan Obat di RS Kepresidenan RSPAD Gatot Soebroto Jakarta. Jurnal Kesehatan Masyarakat (e-Journal) Volume 5, Nomor 4.

- Simamora, R. H. (2018). Buku ajar keselamatan pasien melalui timbang terima pasien berbasis komunikasi efektif: SBAR. Medan: USUpress.

- Simamora, R. H. (2020). Learning of Patient Identification in Patient Safety Programs Through Clinical Preceptor Models. Medico Legal Update, 20(3), 553-556.

- Triwibowo, C., Yuliawati, S., \& Husna, N. A. (2016). Hardover sebagai Upaya Peningkatan Keselamatan Pasien (Patient safety) di Rumah Sakit. Jurnal Keperawatan Soedirman. Vol 11 (2), Hal 77-79. 